\title{
Um Estudo Descritivo das Brincadeiras em uma Comunidade Ribeirinha Amazônica
}

\author{
Daniela Castro dos Reis ${ }^{1}$ \\ Programa de Pós-Graduação em Teoria e Pesquisa do Comportamento da Universidade \\ Federal do Pará, Ananindeua, Pará, Brasil \\ Júlia Almeida Roffé Borges \\ Faculdade de Psicologia da Universidade Federal do Pará, Belém, Pará, Brasil \\ Simone Souza da Costa Silva \\ Núcleo de Teoria e Pesquisa do Comportamento da Universidade Federal do Pará, \\ Belém, Pará, Brasil \\ Leila Said Assef Mendes \\ Escola de Aplicação da Universidade Federal do Pará, Belém, Pará, Brasil \\ Fernando Augusto Ramos Pontes \\ Núcleo de Teoria e Pesquisa do Comportamento da Universidade Federal do Pará, \\ Belém, Pará, Brasil
}

\begin{abstract}
Resumo
A brincadeira é um fenômeno universal que apresenta aspectos peculiares os quais são influenciados por elementos dos ambientes físico, social, cultural e pelas características das crianças. Esses aspectos permitem compreender a brincadeira como produto e produtor do desenvolvimento humano, pois é por meio dela que o indivíduo experimenta, de uma forma segura, comportamentos que, em situações normais, isto é, fora do contexto lúdico, poderiam ter consequências sociais aversivas. O objetivo do trabalho foi o de descrever as brincadeiras ribeirinhas amazônicas. Participaram da pesquisa 66 crianças e adolescentes, moradores da comunidade do rio Araraiana, cuja faixa etária está entre 0 e 18 anos, dos quais 32 meninos e 34 meninas. Utilizou-se o Inventário Sociodemográfico (ISD) e o Inventário Espontâneo das Brincadeiras (IEB). Os dados revelaram uma diversidade de brincadeiras: a brincadeira simbólica, jogos com regras, brincadeira locomotora, brincadeiras com objetos e com animais e brincadeira de construção. Os resultados demonstram que as brincadeiras expressam, em sua maioria, o dia a dia da comunidade como: a construção de brinquedos de barco e espingarda, situações com temas domésticos (cozinha, boneca) e ligados ao meio de subsistência como pescar, conduzir canoa, construir gaiola. Portanto, as brincadeiras de maneira geral retratam aspectos peculiares do ambiente físico, social e cultural do universo infantil da comunidade ribeirinha estudada.
\end{abstract}

Palavras-chave: Brincadeira, Amazônia, comunidade, criança, adolescente.

\section{A Descriptive Study of Child's Play in an Amazonian Riverside Community}

\begin{abstract}
Play is a universal phenomenon which has peculiar aspects which are influenced by elements of the physical, social, and cultural environments by the characteristics of children. These aspects allow us to
\end{abstract}

Endereço para correspondência: Conjunto Cidade Nova V, Travessa WE-29, 622, Coqueiro, Ananindeua, PA, Brasil 67133-120. E-mail: danireispara@yahoo.com.br, julia.roffe@hotmail.com, symon.ufpa@gmail.com leilassef@gmail.com_efarp1304@gmail.com 
understand the joke as a product and producer of human development, because it is through it that the individual experiences in a safe way, behaviors that, in normal situations, ie, outside the play context, could have aversive social consequences. The objective of this study was to describe the Amazonian riverine games. Participated in the study 66 children and adolescents living in the community Araraiana river, whose age is between 0 and 18 years, including 32 boys and 34 girls. We used the sociodemographic schedule (ISD) and the Inventory of Spontaneous Play (IEB). The data revealed a diversity of games: a symbolic play, turbulent / agonistic play, games with rules, locomotor play, play with objects and animals and joke construction. The results demonstrate that the jokes express, mostly day to day community as building toys boat and shotgun situations with domestic issues (kitchen, doll) and linked to livelihood such as fishing, canoeing lead, build cage. Therefore, the games generally portray specific aspects of the physical, social and cultural environment of childhood in the riverside community studied.

Keywords: Play, Amazon, community, child, adolescents.

\section{Un Estudio Descriptivo de Juego en una Comunidad Ribereño Amazonas}

\section{Resumen}

El juego es un fenómeno universal que tiene aspectos peculiares que son influenciados por elementos de los ambientes físicos, sociales y culturales por parte de las características de los niños. Estos aspectos nos permiten entender la broma como un producto y productor del desarrollo humano, ya que es a través de él que las experiencias individuales en una forma segura y comportamientos que, en situaciones normales, es decir, fuera del contexto del juego, podría tener consecuencias sociales aversivas. El objetivo de este estudio fue describir los juegos fluviales amazónicas. Participaron en el estudio 66 niños, niñas y adolescentes que viven en el río Araraiana comunidad, cuya edad está comprendida entre 0 y 18 años, entre ellos 32 niños y 34 niñas. Se utilizó el programa sociodemográfica (ISD) y el Inventario de Juego Espontáneo (IEB). Los datos revelaron una diversidad de juegos: juego simbólico, juegos con reglas, juego locomotor, jugar con objetos y animales y la construcción de broma. Los resultados demuestran que las bromas expresan, sobre todo los días para la comunidad día como barco juguetes de construcción y de escopeta situaciones con cuestiones domésticas (cocina, muñeca) y vinculados a los medios de subsistencia, como la pesca, el piragüismo plomo, construir jaula. Por lo tanto, los juegos generalmente retratan aspectos específicos del entorno físico, social y cultural de la niñez en la comunidad ribereña de estudio.

Palabras clave: Juego, Amazon, comunitarias, niño, adolescente.

A brincadeira é um fenômeno universal (Avedon \& Sutton-Smith, 1971; Parker, 1984; Pellegrini \& Smith, 1998; Santos \& Bichara, 2005; Smith, 1982) que apresenta aspectos peculiares os quais são influenciados por elementos dos ambientes físico, social e cultural bem como pelas características das crianças (Lordelo \& Carvalho, 2006). Para Santos e Bichara (2005), o caráter universal e o caráter específico da brincadeira são complementares, o que permite compreender o brincar como produto e produtor do desenvolvimento humano. É por meio do brin- car que o indivíduo experimenta de uma forma segura, comportamentos que, em situações normais, isto é, fora do contexto lúdico, poderiam ter consequências sociais aversivas. A brincadeira, portanto, é promovedora do desenvolvimento infantil na medida em que cria oportunidades para a criança desenvolver habilidades físicas, afetivas, cognitivas e sociais (Hansen, Macarini, Martins, Wanderlind, \& Vieira, 2007; Marques \& Bichara, 2011).

Para Hansen et al. (2007) e Smith (1982), a brincadeira está presente no repertório compor- 
tamental de espécies que possuem longo período de infância e imaturidade protegida e grande potencial de aprendizagem. É, essencialmente, neste período, que a brincadeira exerce maior influência, contribuindo, em termos funcionais (biológicos), para a sobrevivência do indivíduo humano. Além disso, a brincadeira é uma atividade social e cultural, logo pressupõe um aprendizado (Carvalho \& Rubiano, 2004), ou seja, por meio da brincadeira, participantes de determinados grupos resgatam valores, regras e habilidades sociais fundamentais para o desenvolvimento humano. Para Bussab (2003), a brincadeira possui, ainda, grande valor simbólico e pode proporcionar oportunidades de experiências integrais em termos psicológicos, envolvendo os aspectos afetivos, cognitivos, emocionais, motores e culturais.

Moraes e Otta (2003) ressaltam a importância das diversas funções que a brincadeira apresenta para o desenvolvimento humano, como: treinos de atividades e de papéis, a percepção de pistas sociais, a flexibilidade do comportamento, além da aquisição de valores, normas e crenças da sociedade onde a brincadeira é realizada.

Pensar a brincadeira a partir da universalidade e diversidade permite entender o papel ativo de crianças/adolescentes no processo de transmissão de cultura, o qual envolve a construção de significados veiculados pelos adultos e pelos grupos de pares. Por sua vez, enquanto os atores no processo de desenvolvimento brincam, mudam os significados dos elementos socialmente adquiridos, criando novos significados que passam a ser compartilhados pelo grupo de brinquedos, ou seja, a transmissão cultural ocorre por meio da brincadeira de maneira bilateral. Pontes e Magalhães (2003, p. 15) concordam com esta ideia e conceituam a brincadeira como "rituais que se transmitem, repetidos ou recriados, em ambientes socioculturais distintos".

Entender a brincadeira a partir dessa lógica situa a discussão na interface entre vários campos científicos e considera o indivíduo como co-construtor de conhecimento, de identidade e de cultura o qual sofre variação e se diferencia conforme o contexto em que os atores (brincantes) se desenvolvem. Isto quer dizer que, ao mesmo tempo em que a brincadeira apresenta um caráter universal, ela é também marcada pela especificidade do contexto.

Pode-se dizer, então, que a brincadeira é marcada pelo contexto cultural, por isso promove diferentes modos de desenvolvimento à medida que as vivências se diferenciam de acordo com o contexto. O estudo de Bichara (1999) com 60 crianças na faixa etária de 2 a 12 anos, da comunidade indígena Xocó e da comunidade negra Mocambo, e duas comunidades da região sertaneja do Estado de Sergipe, demonstrou o predomínio dos temas realísticos nas brincadeiras das crianças, inspirados na vida cotidiana daquelas comunidades. Tais aspectos também foram identificados nos trabalhos de Gosso (2004) e Santos e Dias (2010).

O fenômeno da brincadeira tem sido objeto de inúmeras pesquisas que buscam descrever o brincar em culturas e contextos específicos, associando-o ou não com aspectos do desenvolvimento infantil. Em estudos mais atuais, a importância das interações e do contexto cultural na organização social da brincadeira tem sido salientada por diversos autores (Carvalho \& Pedrosa, 2002; Pontes \& Magalhães, 2003; Seixas, 2007; Vickerius \& Sandberg, 2006). Todos esses estudos podem ajudar a pensar sobre as formas variadas de brincar.

Partindo, então, da importância da brincadeira e do contexto no desenvolvimento humano, estudos (Bichara, 1999; Gosso, 2004; Hampton, 1989; Johnson, Christie, \& Yawkey, 1999; Pontes \& Magalhães, 2003; Reis, 2007) têm destacado que os fatores geográficos, socioculturais, econômicos e familiares especificam os modos particulares de se brincar. Para Marques e Bichara (2011), são as variáveis contextuais que atuam como principal fator responsável pela diversidade do comportamento.

Neste sentindo, a diversidade geográfica e cultural do Brasil é palco de diversas formas e conteúdos de brincadeiras, o que constitui um vasto campo de investigação, revelador de aspectos universais e específicos. Apesar da existência, no Brasil, de várias pesquisas psicológicas sobre a brincadeira como produto e produtora de desenvolvimento (Carvalho \& Pedrosa, 2002; Carvalho \& Pontes, 2003; Carvalho \& Rubiano, 2004; Pontes \& Magalhães, 2003), 
constata-se que a maioria desses estudos ainda focaliza contextos urbanos. São poucos os trabalhos desenvolvidos em outros contextos, como comunidades indígenas, negras e ribeirinhas (Bichara, 1999, 2003; Reis, 2007).

A extensão geográfica do Brasil revela diferentes modos de vida e diferentes modos de brincar. Dada a grande diversidade de raças e culturas, é possível a realização de pesquisas não só entre diferentes regiões do país, como também entre grupos culturais distintos dentro de uma mesma região. O Brasil tem, ao mesmo tempo, grandes centros urbanos que incorporam as inovações tecnológicas e cujos valores estão em constante transformação, como também possui muitas comunidades que vivem isoladas, por exemplo, alguns grupos ribeirinhos e comunidades rurais os quais em função do isolamento geográfico preservam tradições e valores culturais. Um exemplo dessa diversidade é o contexto ribeirinho, que se diferencia dos demais em termos físicos e sociais.

Quando se entende que existem contextos distintos de desenvolvimento, é possível pensar em diferentes modos de brincadeira. Então, descrever as brincadeiras encontradas em contextos culturais distintos é imprescindível para se conhecer os processos de desenvolvimento envolvidos nessa atividade, além de possibilitar a compreensão acerca das diferentes formas de desenvolvimento processadas nos ambientes naturais. Pode-se afirmar que crianças do mundo todo brincam, porém o tipo, a maneira, a companhia, as regras, os propósitos, entre outros aspectos, podem variar tanto de um lugar para outro, quanto de criança para criança (Marques \& Bichara, 2011).

Se a brincadeira for pensada como uma adaptação necessária ao tipo de vida dos humanos, requerendo grande variabilidade e flexibilidade comportamental, pode-se fazer uma comparação entre o fato de a brincadeira ser, ao mesmo tempo, universal e diversa (Marques \& Bichara, 2011). Daí a relevância em se buscar compreender os fatores que promovem a variedade/especificidade que se encontra nas brincadeiras. Ainda na concepção de Marques e Bichara (2011), as diversas formas de brincadeiras podem ajudar na compreensão da sua associação às variações e às funções do brincar na infância.

Assim, descrever as brincadeiras do contexto ribeirinho, um espaço miscigenado pelas culturas negra, indígena e branca, localizado, geralmente, à margem de rio e que mantém intrínseca relação de constituição material e identitária com seus elementos socioculturais, significa entender as variações e as funções da brincadeira no referido contexto. Sendo assim, buscou-se investigar as brincadeiras, descrevendo suas práticas em um ambiente peculiar brasileiro, o contexto ribeirinho amazônico.

\section{Método}

\section{Participantes}

Participaram, desta pesquisa, todos os 66 crianças e adolescentes, moradores da comunidade do rio Araraiana, constituindo, assim, 100\% do universo da amostra, com faixa etária entre 0 e 18 anos, dos quais 32 eram meninos e 34 meninas. Divididos nas seguintes faixas etárias: 3 meninos com 3 meses de idade, 9 crianças entre 1-2 anos de idade, sendo 5 meninas e 4 meninos, 4 crianças entre 3 e 4 anos, 2 meninas e 2 meninos, 7 crianças entre 5 e 6 anos, sendo 4 meninas e 3 meninos, 8 crianças com 7 e 8 anos, sendo 4 meninas e 4 meninos, 7 crianças de 9 a 10 anos, sendo 6 meninas e 1 menino, 10 crianças entre 11 e 12 anos, sendo 3 meninas e 7 meninos, 9 adolescente entre 13 e 14 anos, sendo 5 meninas e 4 meninos, 6 adolescentes entre 15 e 16 anos, sendo 3 meninas e 3 meninos, 3 adolescentes entre 17 e 18 anos, sendo 2 meninas e 1 menino.

\section{Ambiente}

A comunidade rural ribeirinha do rio Araraiana localiza-se no Estado do Pará, no Município de Ponta de Pedras, na ilha do Marajó, distante da capital Belém cerca de quatro horas de viagem de barco. Encontra-se isolada, geograficamente, do contexto urbano, cercada pela floresta amazônica e pela baía do Marajó. A principal característica é a produção baseada na economia extrativista, com moradias em sistemas de palafitas, ausência de energia elétrica e a inacessibilidade aos serviços públicos básicos. 


\section{Instrumento e Técnica de Pesquisa}

Para caracterizar a comunidade, utilizou-se o Inventário Sociodemográfico (ISD; Assef-Mendes et al., 2008), constituído pelos itens: identificação dos moradores (nome, idade, estado civil, ocupação, escolaridade, união estável); aspectos domiciliares e familiares.

Para identificar e descrever as brincadeiras ribeirinhas e os grupos de pares envolvidos foi utilizado o Inventário Espontâneo das Brincadeiras (IEB) composto por cinco colunas sendo que na primeira coluna registrava-se o tipo e a nomenclatura da brincadeira; na segunda coluna a companhia (irmãos, primos ou colegas, assim como o gênero e idade); na terceira coluna a identificação do local onde a brincadeira ocorria (escola, terreiro, casa, floresta, campo); na quarta coluna o período de brincadeira (tarde, manhã, noite, mês); e na quinta e última coluna como se desenvolvia a brincadeira (regras e papéis). Ressalta-se que o inventário é caracterizado pelo levantamento não diretivo das brincadeiras, isto é, o registro das brincadeiras foi realizado conforme a nomenclatura local, sendo sempre perguntado aos brincantes o nome de cada brincadeira observada e os demais itens que compõe o instrumento.

\section{Procedimentos}

O contato preliminar com os moradores locais se deu com a ajuda de um informante o qual facilitou o acesso aos moradores e possibilitou a obtenção da autorização para realização da pesquisa. Todos os responsáveis assinaram o consentimento livre e esclarecido que foi aprovado pelo Comitê de Ética de pesquisa com seres humanos e registrado sob o $\mathrm{N}^{\mathrm{o}} 2716 / 06$.

A segunda etapa se deu pela caracterização da comunidade, por meio da aplicação do ISD, que ocorreu durante, aproximadamente, quatro meses, o que contribuiu no fortalecimento do vínculo de confiança com as crianças e adolescentes.

$\mathrm{Na}$ terceira etapa, o pesquisador registrava os dados das brincadeiras observadas no IEB e após a brincadeira, os itens registrados do IEB eram checados com os brincantes. Durante quase 1 ano de coleta de dados, rotineiramente, uma vez por mês, de 5 a 15 dias, diariamente, no horário de 8:00 h às 14:00 h, fazia-se o registro das brincadeiras e a checagem com os brincantes.

\section{Categorias de Análise das Brincadeiras}

As categorias de análise foram pensadas a partir de algumas nomenclaturas já encontradas na literatura. Em função das características dos dados encontrados no contexto pesquisado, utilizou-se categorias sugeridas por Burghardt (1998), Parker (1984) e Piaget (2010), como: brincadeira locomotora, brincadeira com objetos e com animais, brincadeira de construção, brincadeira simbólica e jogos com regras. Essas categorias e suas subcategorias estão apresentadas na Figura 1.
Categorias

Brincadeira locomotora

Brincadeira com objetos e com animais

Brincadeira de Construção

Brincadeira Simbólica

Jogos com regras
Definição das categorias

Brincadeiras como correr e subir em árvores sem a finalidade de uma brincadeira estruturada-livre.

Brincadeiras que envolviam animais e objetos.

Construção de brinquedos, objetos e estruturas físicas.

Constitui o universo de valores, hábitos e convenções/Faz-de-conta.

Envolve brincadeiras de competição.

Figura 1. Quadro das categorias e definição das brincadeiras. 


\section{Resultados}

Os dados foram organizados e são apresentados em dois momentos. $\mathrm{O}$ primeiro referente à caracterização da comunidade e o segundo a identificação e a descrição das brincadeiras partilhadas entre os brincantes ribeirinhos.

\section{Caracterização da Comunidade}

A comunidade está localizada às margens do rio Araraiana, marcada por flora e fauna diversificadas, com grandes núcleos familiares, constituídos por uma rede extensa de parentes e de apoio social, ou seja, a maioria dos moradores possui vínculo de parentesco. A economia de subsistência da comunidade baseia-se em uma cultura extrativista e sazonal, além de ser uma comunidade marcada pelo pouco acesso às políticas públicas, com ausência de serviços nas áreas escolar, da saúde e de saneamento básico.

$\mathrm{O}$ rio Araraiana, com aproximadamente 5 $\mathrm{km}$ de extensão/100 m de largura, pode ser considerado estreito para os padrões regionais. É um "braço" de rio que deságua na baia do Marajó e que apresenta um ciclo de enchente e vazante. Funciona como principal via de locomoção e, ao mesmo tempo, é um importante logradouro para a pesca, servindo, inclusive, como principal distribuidor de água para beber, cozinhar, lavar e brincar. Exerce um fascínio entre as crianças/adolescentes, permeado por histórias de lendas amazônicas. $\mathrm{O}$ respeito e o medo de animais aquáticos, como pirararas (peixe) e jacarés, povoam o imaginário dos brincantes no rio Araraiana.

A comunidade apresenta flora e fauna abundantes, com área predominantemente de florestas, campos alagados e áreas de terra firme. Uma vegetação diversificada da qual a comunidade usufrui dos recursos naturais, como a coleta de frutos, a caça, a pesca e a retirada de matéria-prima para a construção das casas e de alguns brinquedos.

O extrativismo vegetal é uma das principais atividades dessa comunidade. Os produtos nativos mais coletados na mata pelos moradores são: o açaí, a semente de copaíba (Copaifera officinalis) e de andiroba (Carapa quianensis Aubl), e a tala e a palma do miriti. A caça também é outra atividade econômica que possibilita complementar a alimentação. Geralmente, este é uma atividade desempenhada pelo genitor ou provedor da família, sendo realizado no período noturno. Um aspecto interessante dessa atividade é que desde pequenas, as crianças, preferencialmente os meninos, são incentivadas a praticarem esse tipo de atividade. A atividade de pesca, por sua vez, caracteriza-se como artesanal, apresentando um caráter não predatório, com a utilização de técnicas simples para a captura do peixe como: tarrafa, curral ou cacuri, pequenas redes de pesca, matapi, montaria e pequenos barcos. As técnicas de captura de animais são aprendidas e re-produzidas pelas crianças, inseridas desde pequenas nessas atividades, o que pode ser observado nas brincadeiras. A construção de paneiros e peneiras é uma atividade quase que exclusivamente das mulheres e são tecidas com tala de Miriti ou de Jupati, servindo para ajudar na renda familiar, já que são vendidas nas redondezas da região ou aproveitadas nas próprias casas, como utensílios para guardar mantimentos, roupas e outros tipos de objetos.

O modo de vida ribeirinho aponta, portanto, para uma questão central, que é o tipo de ocupação (serviço) que os moradores desempenham na comunidade referida. Segundo os dados demográficos, à ocupação com maior frequência foi de pescador e a segunda extrativista. As mulheres, em sua maioria, responderam que são donas de casa, outras se diziam artesãs, em função da manufatura de paneiro e peneira. As atividades são diferenciadas de acordo com o gênero, as mulheres se responsabilizam com as atividades domésticas e os homens eram encarregados das atividades mais pesadas. Essa função repartida por gênero não é rígida, em algumas famílias as mulheres também pescam, apanham e amassam açaí, o mesmo ocorria entre os homens, que ajudam nas tarefas domésticas, varrendo e passando pano na casa.

Outro aspecto característico da comunidade pesquisada é o sistema social familiar com dinâmica e estrutura específicas. Entre as 22 famílias (125 moradores), sendo 60 adultos e 66 crianças/adolescentes, das quais 28 eram católicos 
(11 meninas e 17 meninos), 34 evangélicos (23 meninas e 11 meninos) e 4 meninos que não declararam a religião. Do total de 22 residências, 17 delas tinham crianças e adolescentes, o que demonstra uma quantidade expressiva daquele grupo na comunidade. O casal era a composição familiar mínima e a máxima composta por 12 membros. As idades dos filhos variavam de 1 a 22 anos e, em alguns casos, com membros de terceira e quarta geração morando juntos.

\section{Descrição das Brincadeiras}

Nesta pesquisa as brincadeiras descritas serão apenas aquelas específicas da comunidade em questão, priorizando assim a descrição das brincadeiras locais e suas especificidades ribeirinhas.

Brincadeira Locomotora. Esta categoria é constituída por brincadeiras de balançar em árvores, nadar, saltar e andar de casco.

1. Balançar em Árvores. Brincadeira de exercício, envolvendo as árvores nativas de grande porte. As crianças/adolescentes penduravam-se com a mão em galhos, balançando-se e pulando para o chão. Subiam tão alto nas árvores, que se tornava impossível observá-las entre os galhos e as folhas das árvores. Essa brincadeira foi identificada, principalmente, entre os meninos mais velhos, em pequenos grupos.

2. Nadar. Apesar da importância do rio na vida das crianças ribeirinhas, essa atividade ocorria, geralmente, na hora do banho e se limitava às margens do rio, próximo aos miritizeiros $^{2}$. Tal brincadeira ocorria em companhia de adultos, irmãos, primos e vizinhos, independente do gênero e em grupo.

3. Salto Mortal. No período de maré cheia, as crianças/adolescentes giravam em torno de saltos, utilizando troncos de árvores como trampolim. Cada brincante esperava o momento de dar o salto mortal, subia no tronco, dava várias piruetas no ar e caía na água. Não havia competição, apenas um clima de

2 Palmeira da região com a qual se constrói brinquedos. descontração e irreverência. Esta brincadeira acontecia independente da idade e do gênero, porém com maior incidência entre as crianças do gênero masculino.

4. Andar de $\mathrm{Casco}^{3}$. Os brincantes direcionavam uma canoa contra a outra, pulando para o seu interior e balançando-a, envolvidos por risadas. Competições entre canoas também foram registradas, tendo como pontos de chegadas locais de referência no rio, como uma árvore caída, ou no porto da escola. Os brincantes mais velhos ajudavam os mais novos, independente do gênero.

Brincadeira de Exercício com Objetos. As brincadeiras de exercício com objetos identificadas: jangada, barquinho e bole-bole.

1. Jangada: Uma espécie de tablado feito de troncos de miriti ou de açaí (material flutuante) construído pelos próprios brincantes. A jangada era utilizada para brincar, o objetivo era manter o equilíbrio sobre a água o maior tempo possível, ou se manter flutuando na água sem afundar. O grupo participante da brincadeira era misto, constituído por irmãos e primos.

2. Barquinho: Objeto confeccionado pelos brincantes com palmeira da região. $\mathrm{O}$ objeto era colocado à margem do rio, e os brincantes observavam a capacidade do equilíbrio e de flutuação do barco o qual era conduzido pela maré e, quase sempre, enroscava-se em algum tronco de árvore ou na margem do rio. Em geral, essa brincadeira acontecia de modo solitário ou, no máximo, com a presença de um parceiro, irmão ou primo. Não houve registro de meninas envolvidas nessa brincadeira, apenas, em alguns casos, como observadoras.

3. Bole-bole: A execução dessa brincadeira se dava com a utilização da semente chamada de olho-de-boi (Ormosia arbórea), comum na região. Os brincantes utilizavam as sementes em quantidade suficiente para caberem nas duas mãos fechadas, em forma de cuia. As sementes eram jogadas para o alto,

Espécie de canoa da região amazônica. 
devendo-se tentar pegá-las com o dorso das mãos, sem deixar cair nenhuma no chão. Essa brincadeira era desempenhada por todas as crianças/adolescente, independente do gênero e idade, mas preferencialmente entre meninas, ocorrendo individualmente ou em grupo.

Brincadeira de Construção. As brincadeiras de construção identificadas na comunidade foram barcos, revólveres, espingardas, gaiolas e bonecas.

1. O Barco: As formas dos barcos variavam, as mais frequentes eram: pesqueiro, pô-pô-pô (barco de transporte de mercadoria e de passageiros) e a rabeta (canoa com motor). Todos construídos com materiais encontrados na natureza como a palma do miriti (Mauritia flexuosa) e troncos de matuti (Terocarpus amazonicus Huber e P. officinalis Jacq.), sendo cada material com sua peculiar forma de tratamento para a construção dos brinquedos. Os barcos de miriti eram facilmente encontrados em exposição em algumas residências como se fossem adereços de decoração do ambiente. $\mathrm{O}$ brinquedo de miriti representa uma das características mais ricas da cultura infantil da brincadeira, não somente no local, mas também na região. A construção dos barcos se dava, em geral, no interior das residências, preferencialmente entre meninos, independente da idade, e na companhia de irmãos ou primos.

2. Revólver e espingarda: Confeccionados com os mesmos materiais dos barcos. A presença desse brinquedo na comunidade estava relacionada à atividade de caça, muito valorizada na região. Diferentemente do contexto urbano, onde não se estimula a brincadeira com armas, no Araraiana, esse brinquedo era valorizado pelos meninos e incentivado pelos pais. A preferência dessa brincadeira era entre os meninos, em companhia de primos e irmãos, com idade que variava de 7 a 17 anos.

3. Gaiolas: A construção de gaiolas estava ligada à atividade, muito comum na comunidade, de prender passarinho, sendo geral- mente construídas para esse fim. A gaiola feita com tala de miriti ou jupati (Raphia taedigera), em forma de um quadrado ou retângulo, tinha a parte inferior feita de palma de miriti em forma de tablado, com as laterais construídas com hastes de tala, arrumadas paralelamente. Seu registro se deu, somente, entre os meninos, independente da idade, porém com alta frequência entre os adolescentes, em companhia dos irmãos ou primos.

4. Maracá: Construído com o ouriço de castanha-do-pará. As crianças inseriam no ouriço pedras ou sementes que, quando balançado, emitia um som estridente e grave. Registrou-se essa brincadeira em um determinado período do ano, caracterizando-a como sazonal, talvez em função do material que só era encontrado em determinada época. Não houve registro de variação de idade ou gênero na sua construção.

5. Boneca: Produzido com diferentes materiais e com uma riqueza de detalhes. A construção desse brinquedo foi registrada estritamente entre as meninas, com idades que variavam de 4 a 17 anos. (a) Boneca de pano: Ensinada pelas mães, era confeccionada com pedaços de tecido, cortados e moldados conforme o corpo humano. As duas partes do molde eram costuradas pelas meninas e enchida com tecidos velhos. Essa brincadeira foi registrada em duas casas. (b) Boneca de tronco de bananeira: Segundo os registros, cortava-se um tronco fino da bananeira e acoplava-se talas de jupati ou miriti, como se fossem braços e pernas. Para a confecção do rosto, eram feitos furos para os olhos e fixados caroços de açaí que representavam nariz e boca. (c) Boneca de vassoura de açaí: Sua construção se dava por meio de cachos secos do açaizeiro, denominados, pela população local, de vassouras de açaí. Como nas vassouras há muitas ramificações finas, separava-se e amarravam-se os talos (espécie de fios que compõem o cacho) ao longo do tronco, criando um corpo, deixando somente alguns fiapos para indicar os braços e as pernas. (d) Boneca de miriti: Construída 
a partir das palmas do buritizeiro (Maurita flexuosa L.), sendo sua confecção similar à da boneca de bananeira. Nesse brinquedo, as faces eram construídas com materiais regionais, como os olhos de sementes de açaí e a boca desenhada com pequenas facas. (e) Boneca de garrafa pet: Feita de garrafas plásticas de refrigerante que eram trazidas pela maré, enchidas com água, para que se tornassem pesadas e se sustentassem em pé. A tampa servia como cabeça e prendia fios ou barbantes compridos que equivaliam a cabelos.

Brincadeira Simbólica. As crianças do Araraiana brincavam de faz-de-conta de variados temas, como: caçada, meios de transporte (barco), temas domésticos (casinha, comidinha e redinha), temas escolares (escola, estudar, lição, professor e taberna), entre outros.

1. Caçada: Ocorria, preferencialmente, entre os meninos e tinha como roteiro original a saída para a mata à procura de caça, fingindo que atiravam em algo. Os grupos variavam quanto à idade, tendo desde crianças pequenas até pré-adolescentes. Em alguns momentos, eles ficavam parados esperando a caça. Esse tipo de brincadeira parece fazer sentido uma vez que a caça é uma das estratégias utilizadas pelos ribeirinhos no auxílio à sobrevivência das famílias.

2. Barco: Presente em quase todas as casas onde viviam meninos, com idade variável desde os menores até os pré-adolescentes (5 a 11 anos). Nessa brincadeira, ocorriam histórias de barqueiros sobre as viagens na baía do Marajó e sobre lendas do rio. Às margens do rio, os meninos criavam narrativas e as interpretavam (faz-de-conta), ondas gigantescas, ataque de botos e peixes, além da presença de tempestades que afundavam os barcos, sempre envolta por risos.

3. Temas domésticos: Faziam parte do imaginário das crianças do gênero feminino. Porém, em uma família, houve o registro de um menino que brincava de casinha com as irmãs ou primas. O papel desempenhado pelo menino era o do provedor da casa, aquele que caçava e trazia o "sustento". Nota-se, que mesmo brincando com uma atividade considerada feminina, o menino representava um papel masculino. Dentro do brincar de atividades domésticas, foram identificados três subtemas: brincadeira de casinha, de comidinha e de redinha, todas com o mesmo roteiro. Identificou-se que elas ocorriam, essencialmente, no terreiro e no interior da casa, dependendo do período sazonal. Redes de tecidos pendurados em pequenos troncos de madeiras, com bonecas de garrafa pet, simulando crianças dormindo. Ao lado, observou-se tampas de garrafas pet imitando utensílios domésticos, como panelas. Quando perguntado sobre os assuntos que ocorriam em volta de tal brincadeira, foi relatado que seria uma reprodução da mãe cozinhando, arrumando a casa, a criança chorando, refletindo, assim, o universo feminino e a rotina diária das mães.

4. Taberna: Nessa brincadeira, as crianças/ adolescentes representavam a venda de produtos como farinha, café, açúcar, óleo, arroz, todos substituídos por materiais encontrados in natura, como: folhas, sementes, pedras. Essa brincadeira ocorria em grupos mistos em gênero e em idade. $\mathrm{O}$ papel principal era o do comerciante, que vendia os mantimentos para as outras crianças as quais conversavam sobre vários assuntos do cotidiano, como a pesca, a caça, a casa, entre outros. O dinheiro era representado por folhas.

Jogos com Regras. Variados tipos de jogos foram identificados na comunidade do rio Araraiana, como: a bandeirinha, macaca, cemitério, apofia, piras, entre outras.

1. Pira: A Pira, brincadeira também presente no contexto urbano, foi identificada na comunidade ribeirinha investigada com o nome pira nas árvores. Sua ocorrência se dava, principalmente, no período da saída da escola, pela manhã e pela tarde, à noite não fora registrada, pois se trata de um local sem energia elétrica. Uma ampla varia- 
ção de idade também foi encontrada, desde crianças com 2 anos até jovens de 19 e 20 anos, de ambos os sexos, em grupos mistos. Uma variação da pira diferente encontrada no contexto urbano foi a pira pega-na-árvore. (a) Pira pega-na-árvore: Nessa brincadeira, foram encontradas várias nomenclaturas, como: pira pega, pira pega-no-açaizeiro, pira mãe e pira rebate, porém com descrições semelhantes $\mathrm{O}$ número de brincantes variava de acordo com a presença de crianças/adolescentes no momento da brincadeira, podendo ser de quatro até doze participantes, entre grupos mistos de meninos e meninas, com restrição a crianças pequenas. A brincadeira foi observada nos terreiros da casa e da escola, principalmente no período vespertino.

Identificou-se que os nomes das brincadeiras mudavam de acordo com a família pesquisada, ou seja, as famílias com maior vínculo de parentesco apresentavam nomenclaturas similares, em contrapartida as famílias que moravam distantes uma das outras nomeavam diferentemente. A finalidade dessa brincadeira é esquivar-se da "mãe", pois caso esta (mãe) alcance qualquer brincante, o mesmo automaticamente exercerá o papel de quem o pegou.

Na pira pega-na-árvore, um dos brincantes sobe na árvore e a "mãe" continua a perseguição atrás, as crianças/adolescentes pulam de uma árvore para outra com o objetivo de não serem pegas pela mãe. Assim, a pira pega pode iniciar no chão, mas, em determinado momento, pode ocorrer nas árvores. Como subir em árvore é uma habilidade que crianças/adolescentes ribeirinhos desenvolvem desde muito pequenos, pode-se dizer que a referida brincadeira é mais uma manifestação dos aspectos próprios e peculiares dessa comunidade. Em geral, pôde-se observar que várias crianças/adolescentes lançavam mão dessa habilidade para tentar fugir da "mãe". No entanto, as crianças menores não praticavam essa modalidade, ficando a cargo somente dos mais velhos, talvez pela maior habilidade e confiança em realizar a perseguição e fuga nos altos.

\section{Discussão}

Em síntese, os dados revelaram que as brincadeiras expressam, em sua maioria, o dia a dia da população da região, com diversas atividades lúdicas tipicamente ribeirinhas, como a construção de brinquedos de barco e espingarda. Outras são representadas por temas domésticos (cozinha, boneca, comidinha) e ligados ao meio de subsistência como pescar, conduzir canoa, construir gaiola, entre outras. Para Lordelo e Carvalho (2006), Santos e Dias (2010), as brincadeiras representam características peculiares influenciadas pelos elementos dos ambientes físico, social, cultural e pelas características das crianças.

Destaca-se, ainda, as semelhanças e diferenças entre as brincadeiras dos ribeirinhos e das crianças de outros contextos, como o faz-de-conta, os jogos de regras, entre outros. Embora o conteúdo destas brincadeiras ribeirinhas seja distinto daqueles encontrados em outros contextos, sua presença revela competências infantis semelhantes às encontradas em outras crianças, como a capacidade imaginativa, a construção da lógica causal, o pensamento abstrato (Vygotsky, 1991). Por outro lado, em todas as brincadeiras foi possível encontrar a marca da peculiaridade contextual como, por exemplo, nas piras-pega realizadas em cima das árvores, nas brincadeiras com barcos construídos pelos brincantes, nas bonecas de garrafas pet, nas brincadeiras como bole-bole, nos saltos, nas explorações nos campos do Marajó e o apofiar.

Além desses aspectos, destacam-se, nas brincadeiras ribeirinhas, a utilização de materiais regionais na construção dos brinquedos e o uso de instrumentos para sua confecção. A utilização dos materiais encontrados no contexto ribeirinho promoveu novos conhecimentos à medida que os brincantes exploram os materiais na execução das brincadeiras e na construção de brinquedos. Para Piaget (2010), o jogo de construção é aquele que a criança cria algo, situando-se entre o jogo e o trabalho (construção).

Os principais materiais identificados nessa brincadeira foram: palmeira da região, tronco de árvores, a vassoura do açaí, sementes como a do bole-bole, até o lixo que os rios traziam como as 
garrafas plásticas pet. Bichara (1999) também identificou uma larga utilização de objetos da natureza (paus, pedras, folhas, areia, etc.), de sucatas, frascos vazios, pedaços de utensílios sem uso. Segundo Mello (1997), a utilização de sucata favorece a construção de significados comuns que devem ser negociados uma vez que não têm um fim determinado. Também Machado (1994) considera que o brinquedo com sucata permite a quem brinca com ele desvendá-lo, ressignificá-lo, pois é um objeto que possui inúmeros significados que não são óbvios, nem estão evidentes, possibilitando, assim, novas e inusitadas relações.

Aliado à regionalidade dos materiais utilizados pela criança/adolescente nas suas brincadeiras, destaca-se a utilização de ferramentas como: facas, terçados, machados, peixeiras e martelos. As crianças/adolescentes tinham acesso a facas e terçados para a fabricação dos brinquedos, aspecto, inclusive, incentivado pelos mais velhos. Para Morais (1989), os artesões dos brinquedos de miriti do município de Abaetetuba utilizam ferramentas rústicas (normalmente facas e facões), esculpem e montam peças segundo suas referências pessoais. Alguns se especializaram em barcos, outros em bonecos dançarinos, cobras, jacarés, madeireiros, pássaros, vaquinhas, aviões, rádios de pilha, televisões etc. A escolha deste ou daquele motivo é parte da realidade individual de cada autor ou família. Pode-se dizer, portanto, que no contexto ribeirinho a utilização de ferramentas na construção de brinquedos faz parte da cultura infanto-juvenil.

$\mathrm{O}$ incentivo à utilização de ferramentas faz sentido haja vista que o contexto ribeirinho promove a inserção das crianças/adolescentes em atividades domésticas e de subsistência, como a pesca, a caça e a coleta. Então, desde cedo, mesmo as menores crianças, adquirem habilidades manuais, aperfeiçoadas na construção de brinquedos, o que se refletia na destreza dos adultos em construir canoas, armadilhas e residências com tamanha habilidade. Isto é, a transmissão de cultura ocorria por meio da construção de brinquedos, de modo que as habilidades no mundo infantil se correlacionavam às habilidades do homem ribeirinho adulto. Isso faz sentido em ter- mos de adaptação ao espaço onde estes vivem, já que o aprendizado dessas habilidades é essencial para a sobrevivência nesse contexto. Para Pontes e Magalhães (2003), o grupo de brincadeira é uma microssociedade, espaço onde se constitui uma rede de relações capazes de atribuir papéis e de trocar conhecimentos, regras, procedimentos que são repassados e recriados pelas crianças.

Esses resultados contribuem para entender o desenvolvimento do homem amazônico tal como ele se apresenta no seu cotidiano, ou seja, como ele é capaz de sobreviver, utilizando-se os recursos da natureza, pescando, coletando, subindo e descendo de árvores, andando sobre troncos e equilibrando-se em pequenos cascos para se deslocar no rio. Os dados encontrados no trabalho de Bichara (1999) evidenciaram que as crianças expressam em suas brincadeiras o modo de vida de seus pais, sofrendo influências em seu desenvolvimento de particularidades culturais e, principalmente, que diferenças socioculturais permitem variabilidade comportamental.

Outro aspecto que pode ser ressaltado é quanto a influência da cultura no desenvolvimento infantil. O modo como as crenças, os valores e as práticas culturais exercem seus efeitos nas práticas de criação de crianças e adolescentes não é suficientemente claro. No entanto, abordagens ao desenvolvimento como a ecológica têm enfatizado as mútuas influências entre o indivíduo e o contexto, inclusive o sistema cultural no qual o desenvolvimento se dá. Para o desenvolvimento humano, especificamente infanto-juvenil, o foco de atenção são os processos bidirecionais entre sujeito e ambiente. Considera-se o desenvolvimento como determinado pela relação entre o organismo e o ambiente circundante, com destaque para a cultura, com seus valores e crenças, neste caso o da comunidade ribeirinha refletidas nas brincadeiras. A relação entre os sujeitos e a cultura é de interinfluência, visto que os seus símbolos e significados são internalizados e modificados no contexto, conforme é percebido nas brincadeiras descritas, trazendo uma série se aspectos da cultura adulta incorporada ao universo infanto-juvenil. Desse modo, as práticas de cuidado e educação de filhos estão diretamente relacionadas com as crenças e valores cons- 
truídos por uma cultura que é, também, produto da história dos indivíduos (Lordelo, Fonseca, \& Araújo, 2000).

Ainda na perspectiva ecológica, há uma ênfase na relação de reciprocidade, de tal forma que mãe e filho se interinfluenciam, assim como são influenciados por outras pessoas, não necessariamente presentes no ambiente físico imediato (Bronfenbrenner, 1979/1996). Dessa forma compreende-se a influência dos aspectos culturais das mudanças desenvolvimentais na criança e no adolescente, mas também nos adultos que cuidam dela e do ambiente em que está inserida.

Outro ponto discutido está relacionado às habilidades ou práticas das crianças/adolescentes ribeirinhos aqui investigados se assemelha ao que é encontrado em outras populações. Provavelmente, isto justifica as semelhanças com os dados de Nunes (2002) que pesquisou crianças A'uwe-Xavante (MT), da aldeia Namunkurá. Ela relatou que os indiozinhos transformam o simples caminhar de um lado a outro em brincadeira. Tais similaridades puderam ser observadas nas brincadeiras das crianças/adolescentes ribeirinhas do Araraiana.

Apesar de contextos semelhantes, os dados encontrados por Gosso (2004) se diferem dos dados aqui relatados. A brincadeira intensa de nadar no rio, identificada em seu trabalho com índios paracanã, é diferente do que foi observado nos ribeirinhos da comunidade do rio Araraiana, que não brincavam intensamente no rio. Collumbine (1950) relatou também baixo índice de ocorrência de brincadeiras na água em povos de clima tropicais. Provavelmente, esta ausência de brincadeiras no rio está diretamente relacionada às lendas locais, compartilhadas pela comunidade, que acreditava na presença de peixes grandes capazes de engolir pessoas.

No entanto, no trabalho com os índios $\mathrm{Pa}$ racanã houve similaridades com os dados encontrados na comunidade do Araraiana. Gosso (2004) identificou algumas brincadeiras de exercício com objetos que eram incorporados às brincadeiras físicas vigorosas que demandavam habilidades e equilíbrio como brincar de flutuar com tábuas ou troncos de árvores.
Ressalte-se, ainda, que o sistema de categorias utilizado neste trabalho se mostrou eficaz na análise dos dados coletados, evidenciando suas especificidades e identificando aspectos similares com brincadeiras que ocorrem em outros contextos. Se por um lado, o sistema de categorias proposto ajudou na descrição das brincadeiras, por outro destaca a necessidade de ser aperfeiçoado a partir das especificidades contextuais de microcontextos que constituem o território brasileiro. Neste sentido, novos estudos precisam ser realizados no intuito de se construir sistemas de categorias capazes de revelar as variações das brincadeiras infanto-juvenis no Brasil.

Apresenta-se, ainda, a limitação da presente pesquisa no que diz respeito à metodologia, visto que se entende que o uso de um número maior de instrumentos de coleta permitiria a construção de um banco de dados mais completo e que poderia ajudar a identificar relações pouco evidentes no estudo aqui apresentado, como a questão do gênero, idade e frequência e a sazonalidade. Outra limitação se refere ao tempo de permanência do pesquisador na comunidade investigada. Acredita-se que sua permanência por um tempo mais prolongado na comunidade possibilitaria o acesso a informações não disponíveis em pouco tempo.

Embora se reconheça as limitações desta pesquisa, o presente trabalho contribui na medida em que seus dados são incorporados no acervo de brincadeiras infanto-juvenis que ocorrem nos diferentes contextos brasileiros. Na realidade, existe um esforço dos pesquisadores nacionais sobre o tema em construir um panorama das práticas dos brincantes no extenso território brasileiro, por acreditar que estas revelam especificidades do desenvolvimento humano. Neste sentido, os dados aqui descritos contribuem com a construção deste retrato nacional.

\section{Referências}

Assef-Mendes, L. S., Pontes, F. A. R., Silva, S. S. C., Bucher-Maluschke, J. S. N. F., Reis, D. C., \& Silva, S. D. B. (2008). Inserção ecológica no contexto de uma comunidade ribeirinha amazônica. Revista Interamericana de Psicologia, 42(1), 1-10. 
Avedon, E. M., \& Sutton-Smith, B. (1971). The study of games. New York: John Willey \& Sons.

Bichara, I. D. (1999). Brincadeira e cultura: O faz de conta das crianças Xocó e do Mocambo (Porto da Folha/SE). Temas de Psicologia, $7(1), 57-64$.

Bichara, I. D. (2003). Nas águas do velho Chico. In A. M. A. Carvalho, C. M. C. Magalhães, F. A. R. Pontes, \& I. D. Bichara (Eds.), Brincadeira e cultura: Viajando pelo Brasil que brinca (pp. 89-107). São Paulo, SP: Casa do Psicólogo.

Bronfenbrenner, U. (1996). A ecologia do desenvolvimento humano: Experimentos naturais e planejados. Porto Alegre, RS: Artes Médicas. (Original publicado em 1979)

Burghardt, G. M. (1998). Conceptions of play and the evolution of animal minds. Evolution and $\mathrm{Cog}$ nition, 5(3), 115-123.

Bussab, V. S. R. (2003). Afetividade e interação social em crianças: Perspectiva psicoetológica (Tese de livre docência, Instituto de Psicologia, Universidade de São Paulo, SP, Brasil).

Carvalho, A. M. A., \& Pedrosa, M. I. (2002). Cultura no grupo de brinquedo. Estudos de Psicologia (Natal), 7(1), 181-188. doi:10.1590/S1413$-294 X 2002000100019$

Carvalho, A. M. A., \& Pontes, F. A. R. (2003). Brincadeira é cultura. In A. M. A. Carvalho, C. M. C. Magalhães, F. A. R. Pontes, \& I. D. Bichara (Eds.), Brincadeira e cultura: Viajando pelo Brasil que brinca (pp. 33-47). São Paulo, SP: Casa do Psicólogo.

Carvalho. A. M. A., \& Rubiano, M. R. B. (2004). Vínculo e compartilhamento na brincadeira de crianças. In M. C. Rossetti-Ferreira, K. S. Amorim, A. P. S. Silva, \& A. M. A. Carvalho (Eds.), Rede de significações e o estudo do desenvolvimento humano (pp. 171-187). Porto Alegre, RS: ArtMed.

Collumbine, H. (1950). Heat prodution and energy requirements of tropical people. Journal of applied Physiology, 2(1), 201-210.

Gosso, Y. (2004). Pexe Oxemoarai: Brincadeiras infantis entre os indios Parakanâ (Tese de doutorado, Universidade de São Paulo, SP, Brasil).

Hansen, J., Macarini, S. M., Martins, G. D. F., Wanderlind, F. H., \& Vieira, M. L. (2007). Brincar e suas implicações para o desenvolvimento infantil a partir da Psicologia Evolucionista. Revista
Brasileira de Crescimento e Desenvolvimento Humano, 17(2), 133-143.

Hampton, J. (1989). Play and development in rural Zimbabwean children. Early Child Development and Care, 47(1), 1-61. doi: 10.1080/ 0300443890470101

Johnson, J. E., Christie, J. F., \& Yawkey, T. D. (1999). Play and early childhood development. New York: Haper Collins.

Lordelo, E. R., \& Carvalho, A. M. A. (2006). Padrões de parceria social e brincadeira em ambiente de creches. Psicologia em Estudo, 11(1), 99-108. doi:10.1590/S1413-73722006000100012

Lordelo, E. R., Fonseca, A. L., \& Araújo, M. L. V. B. (2000). Responsividade do ambiente de desenvolvimento: Crenças e práticas como sistema cultural de criação de filhos. Psicologia: Reflexão e Crítica, 13(1), 73-80. doi:10.1590/S010279722000000100009

Machado, M. M. (1994). O brinquedo de sucata e a criança. São Paulo, SP: Loyola.

Marques, R. de L., \& Bichara, I. D. (2011). Em cada lugar um brincar: Reflexão evolucionista sobre universalidade e diversidade. Estudos de Psicologia (Campinas), 28(3), 381-388. doi:10.1590/ s0103-166x2011000300010

Mello, C. (1997). A interação social na brincadeira de faz-de-conta: Uma análise da dimensão metacomunicativa. Psicologia: Teoria e Pesquisa, 13(1), 199-230.

Moraes, M. S., \& Otta, E. (2003). Entre a serra e o mar. In A. M. A. Carvalho, C. M. C. Magalhães, F. A. R. Pontes, \& I. D. Bichara (Eds.), Brincadeira e cultura: Viajando pelo Brasil que brinca (pp. 187-206). São Paulo, SP: Casa do Psicólogo.

Morais, L. C. (1989). Aprendendo com o brinquedo popular na arte com o Miriti: Um estudo do brinquedo popular. Belém, PA: Secretaria $\mathrm{Mu}-$ nicipal de Cultura.

Nunes, A. (2002). No tempo e no espaço: Brincadeiras das crianças A'uwe-Xavante. In A. Silva, A. V. L. Macedo, \& A. Nunes (Eds.), Crianças indígenas: Ensaios antropológicos (pp. 64-99). São Paulo, SP: Global.

Parker, S. T. (1984). Playing for keeps: An evolutionary perspective on human games. In P. K. Smith (Ed.), Play in animals and humans (pp. 271-293). Oxford, UK: Basil Blackwell. 
Pellegrini, A. D., \& Smith, P. K. (1998). The development of play during childhood: Forms and possible functions. Child Psychology \& Psychiatry Review, 3(2), 51-57. doi:10.1111/14753588.00212

Piaget, J. (2010). A formação do símbolo na criança (4. ed.). Rio de Janeiro, RJ: Zahar.

Pontes, F. A. R., \& Magalhães, C. M. C. (2003). A transmissão da cultura da brincadeira: Algumas possibilidades de investigação. Psicologia: Reflexão e Crítica, 16(1), 117-124. doi:10.1590/ S0102-79722003000100012

Reis, D. C. (2007). Cultura da brincadeira em uma comunidade ribeirinha na ilha do Marajó (Dissertação de mestrado, Programa de Pós-Graduação em Teoria e Pesquisa do Comportamento, Universidade Federal do Pará, Belém, PA, Brasil).

Santos, A. K., \& Bichara, I. D. (2005). Brincadeiras e contextos: Alguns pressupostos para o estudo desta relação. In F. Pontes, C. Magalhães, R. Brito, \& L. W. Martins, Temas pertinentes à construção da Psicologia Contemporânea (pp. 277-297) Belém, PA: Editora da Universidade Federal do Pará.

Santos, A. K., \& Dias, A. M. (2010). Comportamentos lúdicos entre crianças do Nordeste do Brasil: Categorização de brincadeiras. Psicologia: Teoria e Pesquisa, 26(4), 585-594. doi:10.1590/ S0102-37722010000400002
Seixas, A. A. C. (2007). Brincando na Ilha dos Frades (Dissertação de mestrado, Programa de Pós-Graduação em Psicologia, Universidade Federal da Bahia, Salvador, BA, Brasil).

Smith, P. K. (1982). Does play matter? Funcional and evolucionary aspects animal and human play. Behavioral and Brain Sciences, 5(1), 139-184. doi:10.1017/S0140525X0001092X

Vickerius, M., \& Sandberg, A. (2006). The significance of play and the environment around play. Early Child Development and Care, 176(2), 207-217. doi:10.1080/0300443042000319430

Vygotsky, L. S. (1991). A formação social da mente (4. ed.). São Paulo, SP: Martins Fontes.
Recebido: 16/09/2013

$1^{a}$ revisão: $10 / 03 / 2014$ Aceite final: 28/03/2014 